\title{
Ethyl alcohol inhibits habituation of the nictitating membrane reflex response in the intact frog
}

\author{
DENNIS L. GLANZMAN and EUGENE C. SCHMIDT \\ Arizona State University, Tempe, Arizona 85281
}

\begin{abstract}
Habituation of the nictitating membrane reflex response in the intact frog was examined under conditions of various alcohol doses, administered by whole-body immersion into dilute alcohol solutions. Alcohol both markedly reduced the initial response amplitudes and severely disrupted the habituation process in a dose-dependent manner. A theoretical discussion is presented in which the effects of alcohol on habituation in other systems, and the interaction of alcohol with known neural processes, are examined. The results and conclusions are consistent with other reports of presynaptic inhibition modulating habituation at an invertebrate central synapse.
\end{abstract}

The disruptive effect of ethyl alcohol upon many molar behaviors has been well documented in the human literature (e.g., Birnbaum \& Parker, 1977). Likewise, effects of varying concentrations of alcohol upon cellular processes observed in isolated and reduced biological systems have received considerable attention (Davidoff, 1973; Eidelberg \& Wooley, 1970; Faber \& Klee, 1976; Gage, McBurney, \& Schneider, 1975; Kučera \& Smith, 1971). Unfortunately, relatively little information is available concerning the effects of alcohol upon behavioral plasticity in simple and model systems. To this end, we have performed a series of experiments to measure the effects of acute alcohol administration on what is perhaps the simplest form of behavioral plasticity, habituation. We have recently reported an intact preparation in which habituation was readily obtained and accurately quantified (Glanzman \& Schmidt, 1979). The nictitating membrane reflex response of the restrained intact frog can be measured reliably across animals, is unambiguous and robust, and demonstrates the nine parameters of habituation occurring in other vertebrates (Groves \& Thompson, 1970, 1973; Thompson \& Spencer, 1966) and invertebrate (Balderamma \& Maldonado, 1971; Krasne \& Roberts, 1969; Pinsker, Kupfermann, Castellucci, \& Kandel, 1970) species. The frog provides an additional advantage of being able to absorb many pharmaceutical agents, including alcohol, directly

This research was supported by Faculty Grant-in-Aid Awards 983724 and 984021 from Arizona State University to D.L.G. Additional support was provided by National Alcohol Research Center Grant AA 03056 from the National Institute of Alcohol Abuse and Alcoholism (NIAAA), ADAMHA, Washington, D.C. E. C. Schmidt's present address: Scottsdale Community College, $9000 \mathrm{E}$. Chaparral Road, Scottsdale, Arizona 85256. Requests for reprints should be sent to the first author. We thank Phillip Lasiter for assistance with the statistical analysis and Pat Query for typing the manuscript. through the unbroken skin (Ingle, 1973; Kaplan \& Kaplan, 1961; Wass \& Kaplan, 1974).

We were interested in examining the effects of alcohol upon the habituation process per se, irrespective of alcohol effects upon response amplitudes and topographies. A number of potential outcomes were considered: If alcohol merely reduced the amplitude of responses, then one might expect that the amount of relative habituation would increase, since habituation has been characterized as being inversely related to stimulus intensity (and thus to initial response amplitude). If alcohol were to affect the habituation process itself, then an increase or decrease in the amount of relative habituation could occur. If alcohol were to affect only the sensitivity of the preparation to electrical stimulation, a decrease in the amount of relative habituation would occur if the effective stimulus intensity were increased, and an increase in habituation would occur if the stimulus were rendered less effective. And, finally, if alcohol were to affect only the musculature responsiveness, no effect on habituation could be predicted.

\section{METHOD}

\section{Subjects}

All experiments were performed on grass frogs (Rana pipiens) with body weights ranging from 20 to $95 \mathrm{~g}$. The frogs were housed individually in plastic cages measuring $12 \times 27 \times 15 \mathrm{~cm}$, with tap water maintained at a depth of 1 to $2 \mathrm{~cm}$, the water being changed daily. Animals were prepared for testing using techniques detailed elsewhere (Glanzman \& Schmidt, 1979). Briefly, animals were anesthetized by whole-body immersion into a $1 \%$ solution of tricaine methanesulfonate (Sigma Chemical Company \#1626) in tap water, until all musculature was flaccid and no corneal reflexes could be elicited.

\section{Surgery}

Under tricaine anesthesia, a single silk suture (No. 6-0) was tied into the nictitating membrane just beneath the thickened rim, and 
a small loop about $2 \mathrm{~mm}$ in diameter was left in the suture for subsequent attachment of the recording transducer during testing. In addition, two bent stainless steel insect pins $(\# 00)$ were inserted into the superficial skin areas at the inner and outer canthus of the eye to serve as stimulating electrodes. The insect pins thus formed elongated loops (about $2 \mathrm{~mm}$ ), and were located about 3 to $4 \mathrm{~mm}$ both anterior and posterior to the orbit of the eye. At least 2 days were allowed for the animals to recover from suturing and anesthetic effects before testing was commenced.

\section{Apparatus}

Animals were tested in the same apparatus used in earlier experiments (Glanzman \& Schmidt, 1979), a Plexiglas frame designed by Isidore Gormezano. ${ }^{1}$ Animals thus restrained did not begin to struggle severely for upwards of $2 \mathrm{~h}$; a typical recording session would last from 90 to $120 \mathrm{~min}$. The trough of the restraining apparatus was made watertight to allow partial immersion of the animals in dilute alcohol solutions during training.

Electrical stimuli were provided with a Grass Model S5 stimulator. All stimulus pulses were $.20 \mathrm{msec}$ in duration, and intensities were varied from 5 to $12 \mathrm{~V}$. Responses were measured by attaching the silk loop on the lower ridge of the nictitating membrane (NM) through a fine silk thread to a light lever arm connected to a microtorque potentiometer. The potentiometer was wired as a voltage divider, using two mercury batteries as a power source. Nictitating membrane extensions were then read directly as a voltage change at the wiper terminal of the potentiometer. The potentiometer output was dc coupled to a Grass Model 7 polygraph for direct hard copy output, and was also frequency modulated with a Vetter Model 2D FM adaptor and stored on magnetic tape. The polygraph was calibrated so that $1 \mathrm{~mm}$ of NM movement produced $5 \mathrm{~mm}$ of pen deflection. Response amplitudes were read directly from the polygraph records and tabulated for later analysis. Response latencies were measured by playing back the magnetic tape and scoring each latency from oscilloscope traces of the response. This technique allowed a much greater resolution of response latency than was possible from viewing polygraph records.

\section{Procedure}

Each animal received five habituation sessions. The first and last sessions were performed in the absence of alcohol; the second, third, and fourth sessions were counterbalanced for order of alcohol concentration across animals. Three days separated the first (nonalcohol) testing session and subsequent alcohol sessions; at least 6 days separated all remaining sessions. Two of the 11 animals died following the last alcohol session, but before the final nonalcohol session. For these two animals only, comparisons of alcohol tests were made against the first test day without alcohol.

Alcohol was administered by replacing the normal tap water in home cages with the alcohol test solution. Alcohol administration was solely by absorption through unbroken, intact skin (Ingle, 1973). The alcohol concentration of the test solutions ranged from $.125 \%$ to $2.50 \%(\mathrm{v} / \mathrm{v})$. Animals were kept in alcohol solutions for $2.5 \mathrm{~h}$ preceding each testing session. During testing, the trough of the restraining apparatus was partially filled with the pretreatment alcohol solution to keep the animals moist and to maintain alcohol concentrations nearly constant within the animal. ${ }^{2}$

The first test session (nonalcohol) was preceded by a preliminary measurement of the NM responsiveness to determine an appropriate stimulus intensity for each animal. Stimulus intensities were adjusted to yield an approximately half-maximal retraction of the globe and NM extension upwards over the eye, usually about $2 \mathrm{~mm}$, depending upon the size of the animal. The intensity thus chosen for the first day of training was maintained unchanged throughout all subsequent sessions for that animal.

Three separate habituation tests were conducted during each session for each animal. Each test required $7 \mathrm{~min}$, and tests were spaced from 25 to 30 min apart. Each test consisted of six control stimuli delivered at $30-\mathrm{sec}$ intervals, followed by a habituation training sequence of 15 stimuli delivered once per $2 \mathrm{sec}$, and ending with a series of recovery stimuli at $5,15,30,60,120,150$, and $180 \mathrm{sec}$ following the termination of habituation training.

For the remainder of this paper, "control" will refer to the six stimuli presented before habituation training, and "normal" will be used to designate those responses occurring in the first and in the last training sessions, that is, in the absence of alcohol. Data were analyzed in the following way. The amplitude of each response was measured during the habituation series and compared with the mean of the six immediately preceding control responses. The response decrement occurring during habituation was expressed as percent of control amplitude. Thus, the amount of habituation occurring during a given training sequence was [(control amplitude - habituated amplitude)/control amplitude] $\times 100 \%$. This is the familiar "relative habituation" term of Groves and Thompson (1973). A second measure, the final habituated response level, is (habituated amplitude/control amplitude) $\times 100 \%$ and is the most often cited term quantifying habituation, whether referring to the last single response or to the mean of the last few responses of a habituation series. This is the habituation measure most readily apparent in our figures.

When a single score estimate of the amount of relative habituation was needed, the mean amplitude of all 15 responses occurring during the habituation series was used (Glanzman \& Schmidt, 1979). In addition, an analysis of the response latencies and response amplitudes was made for the six control responses in each test. Thus, we had an independent measure of the effects of alcohol upon these response characteristics, unaffected by habituation.

All habituation sessions were preceded by an ancillary measure of alcohol-induced behavioral change. Immediately before habituation training, each animal was tested for the latency it required to right itself after having been placed on its back on a wetted sheet of rough vinyl. A hand-operated timer was used to measure the latency to righting on six successive trials. The animal was then immediately transferred to the testing chamber, and the transducer and electrodes were connected for habituation testing.

\section{RESULTS}

The overall pattern of response decrement occurring during habituation training is shown in Figure 1. The patterns of decrement in response amplitude for the first and last normal sessions, and for the low-, medium-, and high-dose alcohol sessions, show that alcohol reduced the response decrement (i.e., produced less relative habituation) in a dose-dependent manner. Figure 1 also shows the more rapid recovery of responses obtained with alcohol. A statistical test of the dose-dependent effect of alcohol in reducing habituation was performed by summing the response amplitudes for all 15 responses during the habituation sequence (area under the response curve) expressed as percent of control amplitudes. The single scores thus obtained, representing the total relative response occurring during each habituation sequence, were then plotted vs. control alcohol concentration for each animal. This provided a total of three scores for each alcohol concentration and six scores for the alcoholfree condition. The doses used in the plot for each animal were a calculated value, here termed the "dose index".

Small animals (circa $30 \mathrm{~g}$ ) were found to be consistently more sensitive to alcohol than were larger ones 

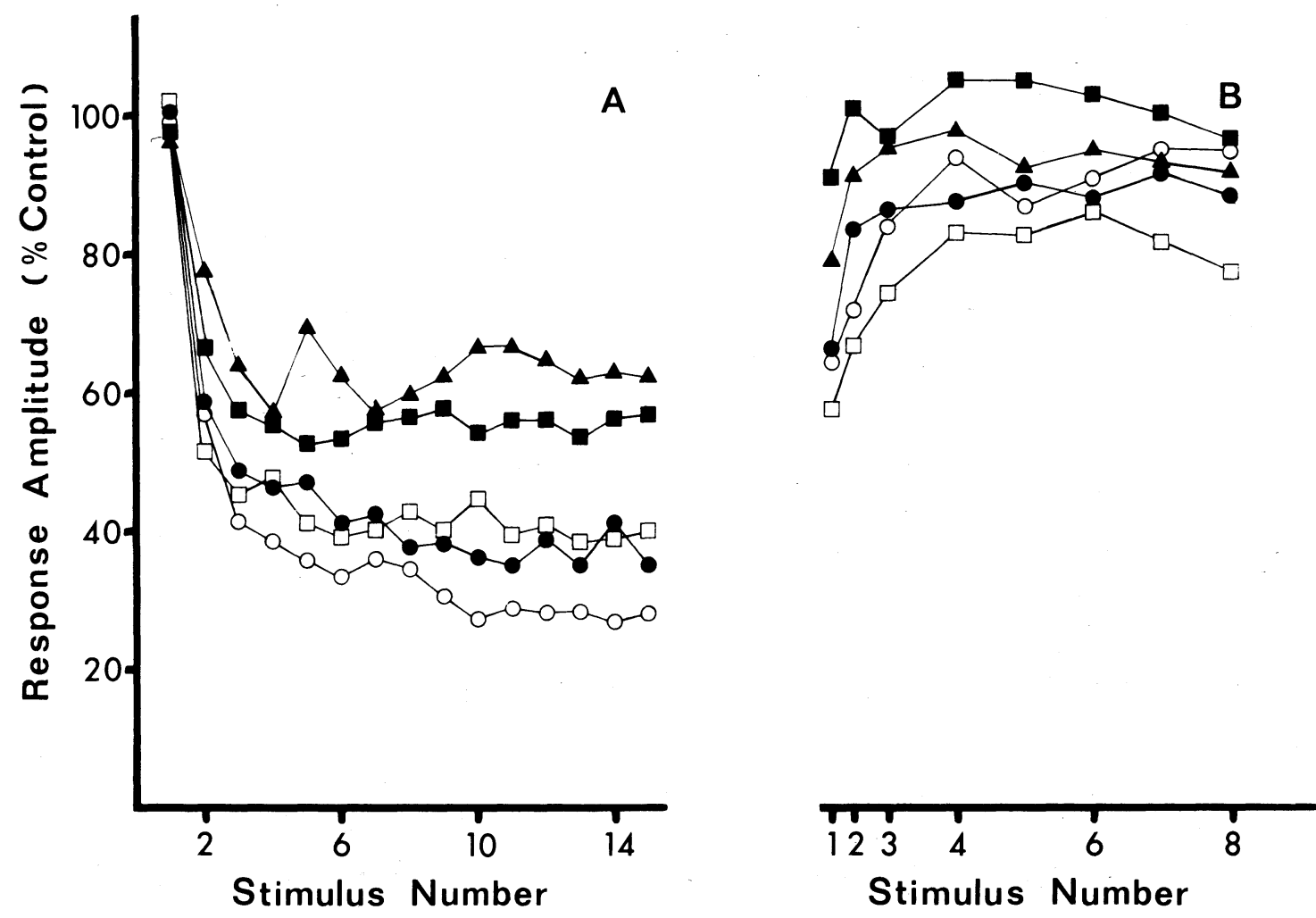

Figure 1. The effects of varying doses of alcohol upon both habituation and recovery processes. Response seen during both the habituation series and recovery period expressed as percent of control amplitudes. Data are collapsed across all animals. Open circles and open squares are the first and last habituation series, conducted in the absence of alcohol. Closed circles, squares, and triangles are the data from habituation series run in low-, medium-, and high-alcohol concentrations (dose indices), respectively.

(circa $80 \mathrm{~g}$ ). The larger surface-to-volume ratio for smaller animals may have accelerated the absorption of alcohol through the skin. The effect was so marked on response amplitudes that a range of alcohol doses was tailored to the weight of each animal. This "dose index" was calculated as follows: alcohol concentration $(\% \mathrm{v} / \mathrm{v})$ multiplied by an estimate of body surface area (body weight raised to the two-thirds power) and multiplied by 5 to give a final dose index between 0 and 1 . Smaller animals (circa $25 \mathrm{~g}$ ) were immersed in lower alcohol concentration solutions (typically $.25 \%$, $.5 \%$, and $.75 \%$ ) than larger animals (e.g., .5\%, 1.0\%, and $1.75 \%$ ).

Some justification for the dose index was obtained by performing a regression analysis on the habituation data (including all tests for all animals), using both the dose index and bath alcohol concentrations as the predictor of the shift in habituation scores. Similar regression analyses were performed on NM response amplitudes and latencies. Both habituation scores and response amplitude regression analyses indicated that dose index was the best predictor of the dose-dependent effects of alcohol when measured by these techniques.

Results of the regression analyses of habituation scores vs. dose index indicated that the slopes of the regression lines for all animals were significantly different from zero $[\mathrm{t}(10)=3.18, \mathrm{p}<.01$, two-tailed
Student's $\mathrm{t}$ test], indicating a clear dose-dependent effect of alcohol in reducing the amount of relative habituation.

High concentrations of alcohol (a high-dose index) caused a marked reduction in the control response amplitudes. Since the same stimulus intensities were used in alcohol and in normal series, the responses often disappeared altogether. This occurrence set an upper limit to the usable alcohol doses for habituation tests in each animal.

The six control responses preceding each habituation series were also used in determining the behavioral effects of alcohol upon NM responsiveness independent of habituation. Figure 2 shows the mean of amplitude and latency measurements of control NM responses at various alcohol doses, expressed as percent of the mean control response measures in the absence of alcohol. Both amplitude and latency of responses decreased marginally with increasing doses of alcohol. Neither of these effects was significant when the individual test averages were subjected to the regression analysis described above [amplitude: $\mathrm{t}(10)=1.03$, $\mathrm{p}>.20$; latency: $\mathrm{t}(10)=1.34, \mathrm{p}>.20)$.

For some animals, even the lowest doses of alcohol reduced response latencies down to within 10 to $15 \mathrm{msec}$ of stimulus presentation. Apparently, this was a minimum value from which no additional reduction 


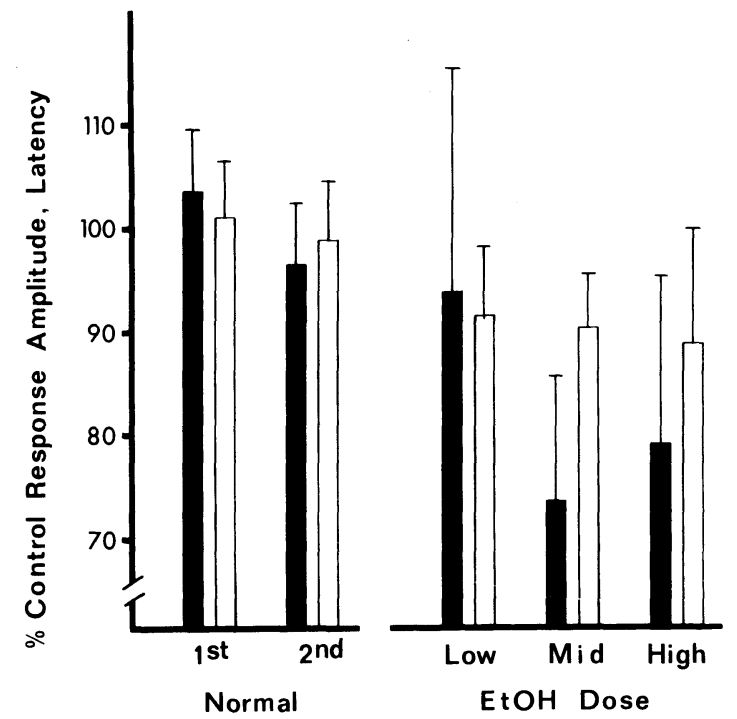

Figure 2. Amplitude (solid bars) and latency (open bars) measurements of control responses ( \pm SEM) comparing normal vs. alcohol series. Data points are collapsed across all series and all animals. Note that both amplitude and latency of the nictitating membrane reflex responses decrease with increasing alcohol dose indices.

could be obtained. In normal trials, response latencies averaged $18.5 \mathrm{msec}$ and seldom exceeded $35 \mathrm{msec}$ even for the smallest amplitude responses. However, the trends are of special interest for several reasons. A comparison of mean latencies vs. mean amplitude for the six control responses in each normal session resulted in a strong inverse correlation $[\mathrm{r}(52)=-.611$, $\mathrm{p}<.001$, Pearson $\mathrm{r}$ correlation coefficient]. The same inverse correlation between response latency and amplitude was also observed in nine tests under alcohol $[\mathrm{r}(88)=-.631, \mathrm{p}<.001]$.

Since latencies normally increase as response amplitudes decrease, the decrease in both amplitude and latency suggests possible competing and conflicting effects of alcohol. Although alcohol showed a nonsignificant tendency to reduce both amplitude and latency, the same inverse relationship between these two response parameters persisted at all alcohol concentrations tested.

The relationship between control response amplitude and habituation is even more important. Intense stimuli that yielded higher amplitude control responses normally yield decreased relative habituation (Glanzman \& Schmidt, 1979; Groves \& Thompson, 1970, 1973; Thompson \& Spencer, 1966). For example, the reduction of relative habituation seen with alcohol in Figure 1 could routinely be approximated by a $10 \%$ to $15 \%$ increase in the stimulus intensity (Glanzman \& Schmidt, 1979). Although stimulus intensity was held constant across all tests for a given animal, it may be possible that the observed decrease in relative habituation found with alcohol was the result of increased sensitivity to the stimulus. This should have been accompanied by a simultaneous increase in control response amplitudes, however, instead of the observed decreases.

Individual data for a small (26 $\mathrm{g})$ animal are plotted as a function of alcohol dose index in Figure 3. Figure 4 shows the relative habituation data plotted

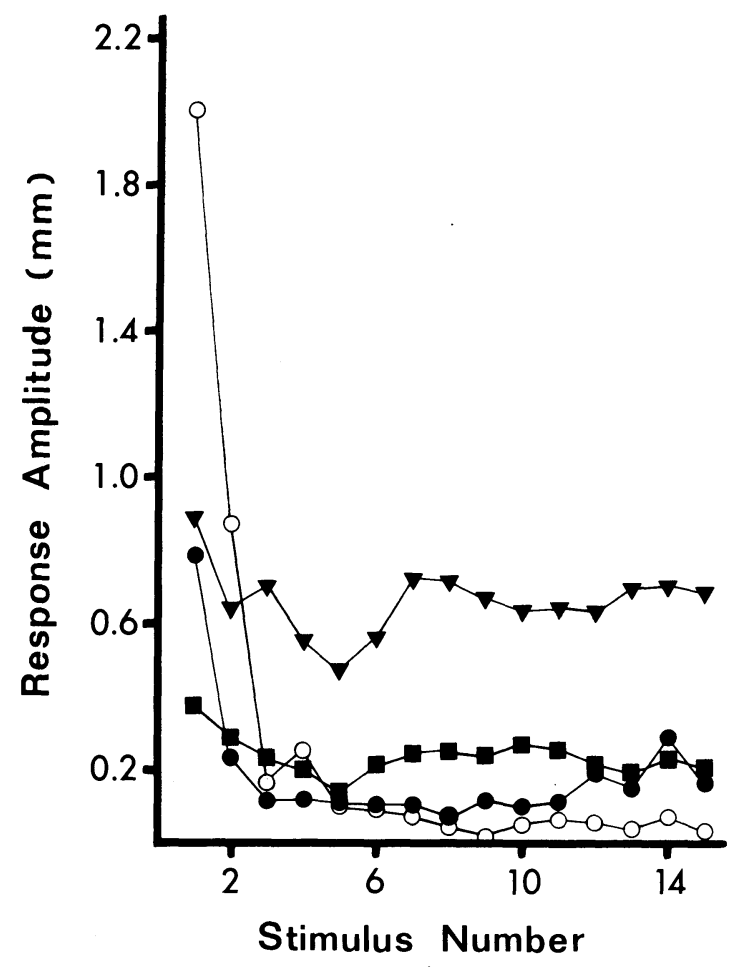

Figure 3. Habituation data from a single small $(26 \mathrm{~g})$ animal plotted for all alcohol series. Normal data $(O)$ are from Day 1 , alcohol habituation in the presence of $\operatorname{low}(\bullet)$, medium $(\square)$, and high $(\nabla)$ dose indices. Note especially that both the initial response amplitude and the amount of absolute habituation are reduced by successively higher alcohol dose indices.

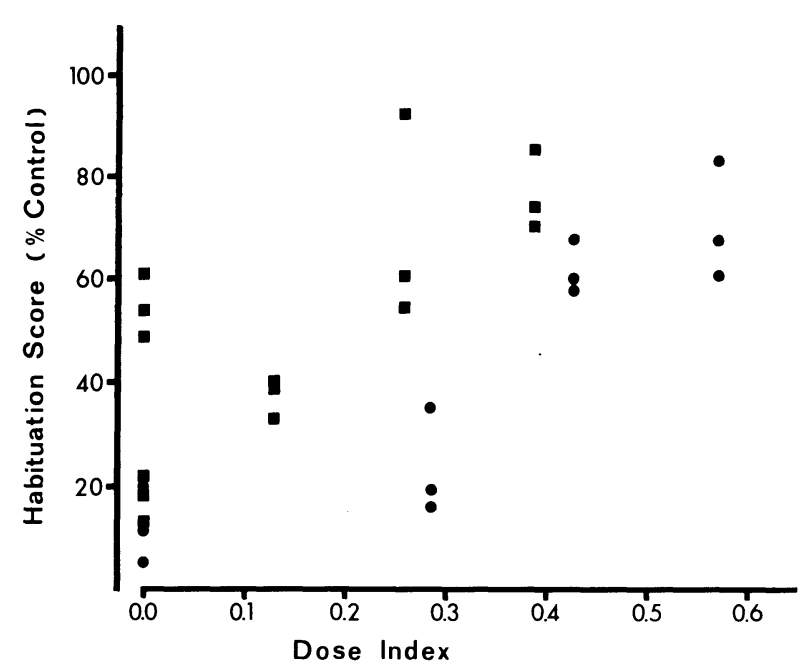

Figure 4. Data from a large $(\square)$ and a small $(\bullet)$ animal analyzed as a single response measure for each habituation series (see text for explanation) plotted as a function of alcohol dose index. Decreased relative habituation is demonstrated as an increased habituation score. 
against dose index for the same animal. Figures 5 and 6 show similar plots of the average amplitude and latency of the control responses for each test. Typical within- and between-session variability can be seen in these plots. The effect of alcohol on increasing the time to righting was most pronounced. A comparison of righting latency with dose index was also performed and yielded a highly significant correlation $[\mathrm{r}(34)=$ $.647, \mathrm{p}<.005]$. The regularity of this effect, which was assessed separately from the NM response measures, suggests that the high variability in the NM

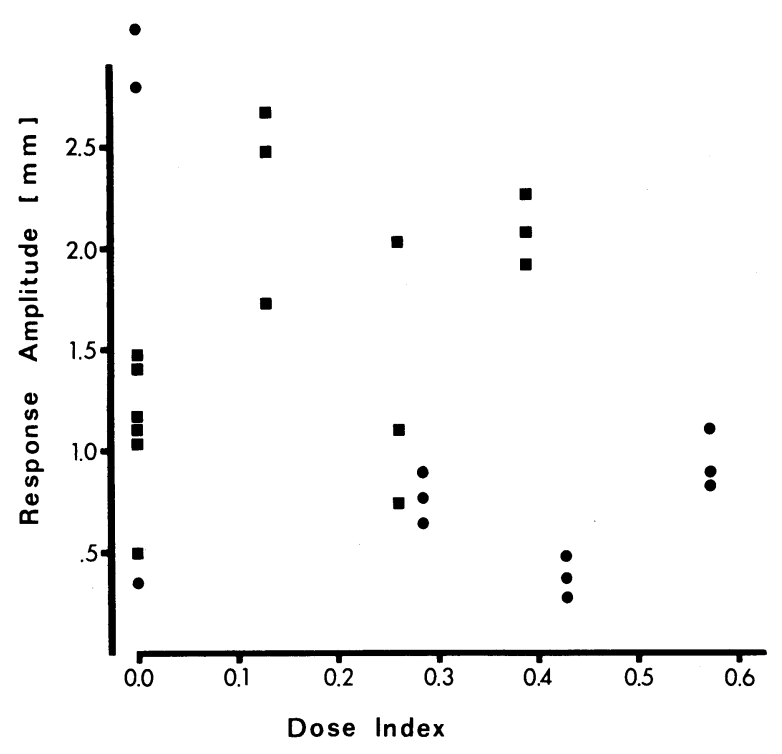

Figure 5. Absolute response amplitudes (mm) measured for a single large $(\square)$ and a single small $(\bullet)$ animal as a function of dose index.

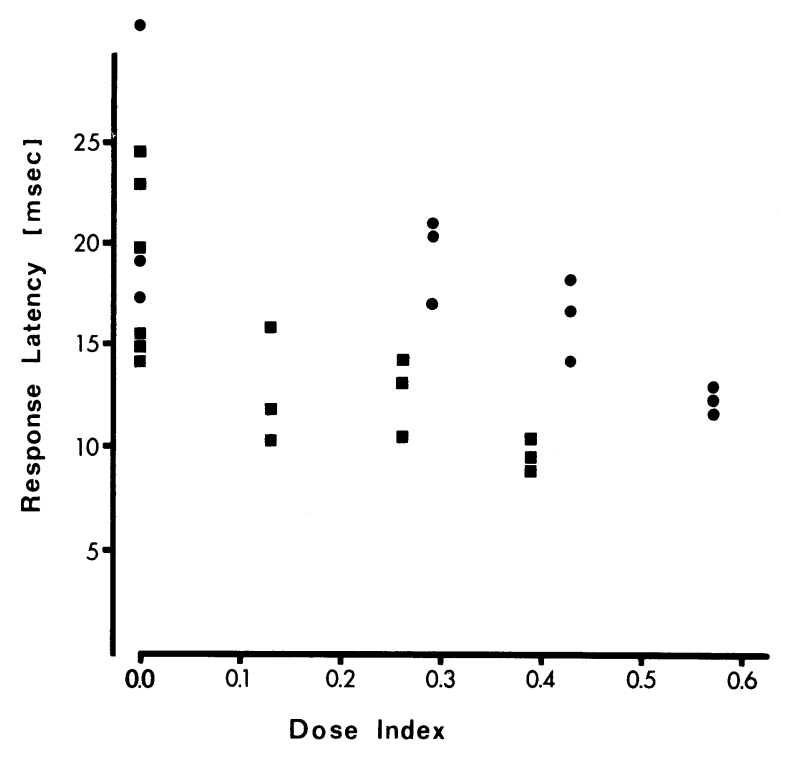

Figure 6. Response latencies from the same animals depicted in Figure 5. Note that response latencies decrease slightly with increasing dose index. measures might be attributable in part to the apparatus and/or methodology of the NM reflex testing rather than to the alcohol administration alone. For example, the effect of alcohol on righting correlated only poorly with the habituation effect $[\mathrm{r}(34)=.309, \mathrm{p}<.10]$ and with the amplitude effect $[\mathrm{r}(34)=.345, \mathrm{p}<.05]$.

\section{DISCUSSION}

A reliable dose-dependent effect of alcohol in reducing relative habituation has been observed in the frog NM reflex response. The magnitude of effect was not particularly large, although possibly somewhat mitigated by the large variance in response measures. The decrease in relative habituation cannot be attributed to increased responsiveness, in that alcohol always produced a decreased response amplitude. Reduced response amplitudes in alcohol-treated preparations were accompanied by a surprising, but not significant, trend toward decreased response latencies. There was an indication that the dose-dependent effect of alcohol was closely related to the size of the animal. Smaller animals required lower doses of alcohol to produce similar effects both on habituation and on the more predictable measure of decreased righting ability.

The observed decrease in response amplitude during control periods under alcohol could result from a number of factors, including decreased conductivity of the efferent motor fibers (Moore, Ulbricht, \& Takata, 1974), decreased afferent conductivity (Armstrong \& Binstock, 1964), decreased synaptic efficacy (Erickson \& Graham, 1973; Phillis \& Jharmandas, 1971), or alterations in responsivity of the musculature involved in the production of the reflex (Knutsson, 1961).

The standard error bars of Figure 2 indicate that the variance of responses collected under alcohol conditions was considerable. There was much smaller variance in the two nonalcohol control sessions. Thus, the methodology must be considered a prime source of variance in the data, since the measures of the first normal session were seldom reliably replicated in the second normal session some weeks later.

In spite of the large variability across measures, the general results of the study were noteworthy. When NM response amplitudes were reduced to very low levels by alcohol, little or no habituation was observed (responses remained at or near control levels). The pattern of effects broadly matches that found in a quite different preparation, one in which the lateral column to the motoneuron monosynaptic pathway is isolated from the spinal cord (Glanzman \& Epperlein, Note 1).

The observed decrease in both response amplitude and response latency was highly unusual. In normal preparations, reducing stimulus intensity results in a decreased response amplitude but an increased latency (Glanzman \& Schmidt, 1979). We have as yet no explanation for this unexpected effect. 
As stimulus intensity is increased, so too is response amplitude. We have used initial (control) response amplitudes as an indirect measure of stimulus intensity in alcohol-treated preparations. Previous work with this preparation (Glanzman \& Schmidt, 1979) and with the isolated spinal cord preparation (Glanzman \& Epperlein, Note 1) has shown that initial response amplitude is indeed a valid measure of stimulus intensity, at least insofar as predicting the amount of relative habituation that will result from iterated stimulation. The concomitant decrease in response amplitude and amount of relative habituation is inconsistent with earlier reports of habituation being inversely related to stimulus intensity (e.g., Thompson \& Spencer, 1966) or to control response amplitudes (Glanzman \& Schmidt, 1979). If the decreased response amplitude under alcohol conditions reflects a desensitization of the preparation to the applied stimulus, then an increase in the amount of relative habituation produced should have occurred.

In view of the above observations, two conclusions are possible: First, the initial response amplitude measure is invalid in terms of making a comparison with Thompson and Spencer's stimulus intensity characteristic of habituation. Second, some process or processes are occurring within the neural pathways mediating the NM reflex that affect habituation differently from response amplitudes and/or latencies. Results reported earlier (Glanzman \& Schmidt, 1979) indicate that initial response amplitude is indeed a reliable predictor of the amount of relative habituation to be produced in this preparation. We are then left with the as yet unanswered question of alcohol's effects on response plasticity.

\section{Theoretical Discussion}

The dose-dependent effects of alcohol fall into two broad categories, response facilitation (usually observed at low alcohol doses or concentrations) and response decrement (at higher doses). The plethora of information available regarding cellular effects of alcohol on various aspects of nervous system functioning has served only to obfuscate any determination of the mechanism(s) by which response plasticity is affected. For example, at the frog and rat neuromuscular junction, alcohol has been found to increase both the frequency and amplitude of spontaneous miniature endplate potentials and of endplate potentials following stimulation (Gage, 1965; Inoye \& Frank, 1967; Okada, 1967). The release of acetylcholine from motor nerve collaterals onto Renshaw cells has also been determined indirectly by measuring Renshaw cell firing rates, and has been shown to be increased by alcohol (Benecke, Meyer-Lohmann, Hagenah, \& Hellweg, 1972; Meyer-Lohman, Hagenah, Hellweg, \& Benecke, 1972). Similarly, alcohol has long been recognized as a weakly analgesic compound (e.g., Ritchie, 1975), such that the effects on response ampli- tudes might in part be due to a decrement in stimulus effectiveness or in conduction and/or transmission along afferent pathways.

Davidoff (1973) has reported that alcohol markedly potentiates primary afferent depolarization in the isolated frog spinal cord, and has proposed that this effect is due to an increased efficacy of GABA(gamma aminobutyric acid)-mediated presynaptic inhibition. If this effect were also occurring in the polysynaptic pathway mediating the nictitating membrane reflex, then a decrease in response amplitude could be expected from depolarization of afferent sensory terminals. Krasne and Bryan (1973) have shown that in the crayfish tail-flick response pathway, presynaptic inhibition of afferent sensory fibers in fact protects the stimulated pathway from habituation. Additionally, when GABAmediated presynaptic inhibition is blocked by picrotoxin in the lobster tail-flick preparation, the response habituates more rapidly than it does normally (Krasne $\&$ Roberts, 1969). From these data, and our own, a parsimonious model of presynaptic influences on habituation may be formed, which would conform to our current model of habituation (Glanzman \& Thompson, 1979, 1980).

If alcohol mimics or potentiates the effects of GABA in promoting a partial depolarization of afferent terminals, then the effect of reducing the amount of habituation produced during a testing session under alcohol could be compared with Krasne and Bryan's (1973) report of normal presynaptic inhibition reducing the amount of habituation produced at crayfish central synapses.

This is not inconsistent with current theories of homosynaptic depression underlying habituation at central monosynaptic pathways in both vertebrate (Groves \& Thompson, 1970, 1973) and invertebrate (Kandel, 1976) preparations. If the overall activity of a single presynaptic terminal were in some way directly related to the amount of habituation produced at that synapse, then reduction of the total amount of activity within that terminal by alcohol could conceivably produce less relative habituation. (This should not be confused with the inverse habituation-intensity relationship of Thompson and Spencer, 1966, which occurs in multiple neuron pathways, whether mono- or polysynaptic. In such pathways, high-threshold elements may be much more resistant to habituation than more sensitive elements, thus accounting for the inverse relationship between stimulus intensity and habituation, as proposed by Zucker (1972) for crayfish monosynaptic pathways.)

The few other reports of alcohol interactions with habituation have yielded essentially similar results. Berthoz, Young, and Oliveras (1977) have reported that habituation of vestibular nystagmus in the cat is markedly reduced by .2 to $2.0 \mathrm{~g} / \mathrm{kg}$ alcohol (iv). Collins, Schroeder, and Hill (1973) have commented that alcohol can enhance vestibular response by releasing a 
"central habituating mechanism." Aschan (1967) reported the effects of alcohol on habituation of postrotatory nystagmus in humans: "Eight out of ten test subjects in whom the maximal blood alcohol concentration ranged from 0.52 to $0.95 \%$, all showed a disappearance of the nystagmus cupulogram response decline."

Our own experiments demonstrate a highly significant effect of ethyl alcohol on reduction of relative habituation of the frog nictitating membrane reflex response. The strong decremental effect parallels that reported by Ingle (1973), who examined habituation of prey-catching activity in the intact frog. He reported a large reduction in habituation of this behavior by alcohol, but his studies did not examine other aspects of this response (e.g., coordination, number of hits/ misses, speed of lunging, etc.). Ingle assumed that reduction of habituation of prey-catching activity by alcohol "reflects an alcohol-induced disinhibition within the frog's visuomotor mechanism-very probably within the optic tectum'" (p. 128).

Ingle (1973) has also cited a report of similar habituation deficits produced by placing large lesions in the caudal thalamus (Ewert, 1970), and a report showing that the production of similar "automation" behavior can be produced by the topical application of strychnine to the optic tectum (Stevens, 1969). By combining these data, it would be tempting to speculate that habituation of prey-catching activity could be blocked by the removal of inhibition within the optic tectum, possibly arising from fibers projecting from the caudal thalamus (Ewert, 1970), and that this inhibition may be effectively blocked by strychnine (Stevens, 1969). If strychnine functions in the frog optic tectum in the same way that it appears to function in the mammalian spinal cord, by blocking glycine-mediated postsynaptic inhibition onto motoneurons (Aprison, Davidoff, \& Werman, 1970), then it might be reasonable to propose that this example of behavioral habituation is mediated by glycine-induced postsynaptic inhibition of optic tectum neurons by fibers arising from the caudal thalamus.

This is a most interesting possibility and not without precedent in other polysynaptic models of habituation. For example, both Wall (1970) and Wickelgren (1967) have proposed that a "build-up" of postsynaptic inhibition may underlie habituation of the polysynaptic spinal reflex arc in the acute spinal cat preparation. This was based upon Wickelgren's observation of unidirectional transfer (or generalization) of habituation across two independent stimulus inputs.

Pearson and MacDonald (1973) have reported that habituation of integrated electromyogram activity in the rat biceps femoris muscle, in response to stimulation of ipsilateral hindpaw skin, was reduced in the presence of strychnine. Their statement that, although strychnine "did not cause any enhancement of the responses to the initial stimuli as compared to the control rats $(t=0.97 ; p<0.10)$, it did result in an impairment of habituation to subsequent stimuli," is not supported by visual inspection of the data presented in their Figure 1 (p. 452). They reported only the results of a single $t$ test performed on the initial data (response amplitudes of the first 10 trials of the habituation series) in normal vs. strychnine-treated animals. A more rigorous analysis (Curry, 1975) based on digitization of data points in their figure yielded no significant difference in either the rate or amount of habituation produced under strychnine.

In their experiment, animals were continuously infused with strychnine ( $30 \mu \mathrm{g} / \mathrm{kg} / \mathrm{min})$ beginning $20 \mathrm{~min}$ prior to the first habituation stimulus, and upwards of 300 stimuli were presented at 10 -sec intervals. Thus, by the time the first stimulus of the habituation series was presented, animals had received $600 \mu \mathrm{g} / \mathrm{kg}$ strychnine; by the 300th stimulus, they had received a total of $2,100 \mu \mathrm{g} / \mathrm{kg}$. At the end of the habituation training period (after 70 min of continuous strychnine infusion), the animals may have had several times the circulating strychnine levels as at the beginning of the habituation tests. Thus, increased strychnine concentration alone could account for the larger response amplitudes (impairment of habituation?) occurring at the end of their habituation testing session. Using the figures of Adamson and Fouts (1959) for hepatic metabolism of strychnine, it may be estimated that after 70 min of such continuous infusion the animals had a circulating strychnine concentration at least three times greater than that which was present at the outset of habituation testing. Unfortunately, they reported no control procedure to examine this possibility, nor did they report any attempt to measure blood strychnine levels during the experiment.

Conversely, Spencer, Thompson, and Neilson (1966) have demonstrated that neither picrotoxin, which blocks some forms of presynaptic inhibition, nor strychnine alters habituation of the polysynaptic spinal reflex arc in the acute spinal cat. Similarly, Glanzman, Groves, and Thompson (1973) have shown, indirectly, that postsynaptic inhibition of spinal motoneurons in the acute spinal cat does not occur during the development of habituation. The majority of evidence now favors another mechanism of habituationhomosynaptic depression of those elements mediating the response (e.g., Glanzman \& Thompson, 1979, 1980; Kandel, 1976).

We are currently undertaking several studies in an attempt to determine the mechanisms of alcoholinduced changes occurring in a habituating monosynaptic pathway in the isolated spinal cord of the frog (Glanzman \& Epperlein, Note 1). Preliminary indications are that the parameters of response amplitude and amount of relative habituation are similarly affected in this reduced model system: Control amplitudes are reduced, relative habituation is severely decremented, and response recovery is prolonged. By 
examining behaviors in intact animals and electrophysiological responses in model systems, we are making a concerted attempt to elucidate the mechanism(s) by which ethyl alcohol exerts its detrimental effect on this most simple form of behavioral and neural response plasticity.

\section{REFERENCE NOTES}

1. Glanzman, D. L., \& Epperlein, R. C. Disruption of monosynaptic habituation by ethyl alcohol. Manuscript submitted for publication, 1980.

2. Rinaldi, P., \& Thompson, R. F. Personal communication, 1980.

\section{REFERENCES}

Adamson, R. H., \& Fouts, J. R. Enzymatic metabolism of strychnine. Journal of Pharmacology and Experimental Therapeutics, 1959, 127, 11-24.

Aprison, M. H., Davidoff, R. A., \& Werman, R. Glycine. Its metabolic and possible transmitter roles in nervous tissue. In A. Lajtha (Ed.), Handbook of neurochemistry (Vol. 3). New York: Plenum Press, 1970.

Armstrong, C. L., \& Binstock, L. The effects of several alcohols on the properties of the squid giant axon. Journal of General Physiology, 1964, 48, 265-273.

Aschan, G. Habituation to repeated rotatory stimuli (cupulometry) and the effect of antinausea drugs and alcohol on the results. Acta Oto-Laryngologica, 1967, 64, 95-106.

Balderamma, N., \& Maldonado, H. Habituation of the deimatic response in the mantid (Stagmatopera biocellata). Journal of Comparative and Physiological Psychology, 1971, 75, 98-106.

Benecke, R., Meyer-Lohmann, J., Hagenah, R., \& Hellweg, C. Antagonism of pyrithinol- $\mathrm{HCl}$ to ethyl alcohol at a spinal cholinergic synapse. Zeitung Rechtsmedicin, 1972, 70, 89-93.

Berthoz, A., Young, L., \& Oliveras, F. Action of alcohol on vestibular compensation and habituation in the cat. Acta Oto-Laryngologica, 1977, 84, 317-327.

Birnbaum, I. A., \& Parker, E. S. (Eds.), Alcohol and human memory. Hillsdale, N.J: Erlbaum, 1976.

Collins, W. E., Schroeder, D. J., \& Hill, R. J. Some effects of alcohol on vestibular responses. Advances in Otorhinolaryngology, 1973, 19, 295-308.

Curry, R. E. A random search algorithm for laboratory computers. Behavior Research Methods \& Instrumentation, 1975, 7, 369-376.

DAvidoff, R. A. Alcohol and presynaptic inhibition in an isolated spinal cord preparation. Archives of Neurology, 1973, 28, 60-63.

Eidelberg, E., \& Wooley, D. F. Effects of ethyl alcohol upon spinal cord neurons. Archives of International Pharmacodynamics, 1970, 185, 388-396.

Erickson, D. K., \& Graham, D. T. Alteration of cortical and reticular acetylcholine release by ethanol in vivo. Journal of Pharmacology and Experimental Therapeutics, 1973, 185, 583-593.

EwERT, J. -P. Neural mechanisms of prey catching and avoidance behavior in the toad (Bufo bufo L.). Brain Behavior Evolution, 1970, 3, 36-54.

FABER, D. S., \& KLEE, R. Ethanol suppresses collateral inhibition in the goldfish Mauthner cell. Brain Research, 1976, 104, 347-353.

GAGE, P. W. The effect of methyl, ethyl and n-propyl alcohol on neuromuscular transmission in the rat. Journal of Pharmacology and Experimental Therapeutics, 1965, 150, 236-243,

Gage, P. W., McBurney, R. N., \& Schneider, G. T. Effects of some aliphatic alcohols on the conductance change caused by a quantum of acetylcholine at the toad end plate. Journal of Physiology (London), 1975, 244, 409-429.

Glanzman, D. L. Synaptic mechanisms of habituation (Doctoral dissertation, University of California, 1976). Dissertation $A b$ stracts International, 1976, 37, 1478B-1479B. (University Microfilms No. 76-19, 626)

Glanzman, D. L., Groves, P. M., \& Thompson, R. F. Stimulus generalization of habituation in spinal interneurons. Physiology \& Behavior, 1972, 8, 155-158.

Glanzman, D. L., \& Schmidt, E. C. Habituation of the nictitating membrane reflex response in the intact frog. Physiology \& Behavior, 1979, 22, 1141-1148.

Glanzman, D. L., \& Thompson, R. F. Evidence against conduction failure as the mechanism underlying monosynaptic habituation in frog spinal cord. Brain Research, 1979, 174, 329-332.

Glanzman, D. L., \& Thompson, R. F. Alterations in spontaneous miniature potential activity during habituation of a vertebrate monosynaptic pathway. Brain Research, 1980, 189, 377-390.

Groves, P. M., \& Thompson, R. F. Habituation: A dual-process theory. Psychological Review, 1970, 77, 419-450.

Groves, P. M., \& Thompson, R. F. A dual process theory of habituation: Neural mechanisms. In H. V. S. Peeke \& M. J. Herz (Eds.), Habituation (Vol. 2): Physiological substrates. New York: Academic Press, 1973.

INGLE, D. Reduction of habituation of prey-catching activity by alcohol intoxication in the frog. Behavioral Biology, 1973, 8, 123-129.

INOYE, R., \& FrANK, G. B. Effects of ethyl alcohol on excitability and on neuromuscular transmission in frog skeletal muscle. British Journal of Pharmacology, 1967, 30, 186-195.

KANDEL, E. R. The cellular basis of behavior. San Francisco: Freeman, 1976.

Kaplan, H. M., \& Kaplan, H. Anesthesia in frogs with ethyl alcohol. Proceedings of Animal Care Panel, 1961, 11, 31-36.

KNUTSSON, E. Effects of ethanol on the membrane potential and membrane resistance of frog muscle fibers. Acta Physiologica Scandinavica, 1961, 42, 242-253.

Krasne, F. B., \& Bryan, J. S. Habituation: Regulation through presynaptic inhibition. Science, 1973, 182, 590-592.

Krasne, F. B., \& Roberts, A. Habituation of the crayfish escape response during release from inhibition induced by picrotoxin. Nature, 1969, 215, 769-770.

KučerA, J., \& Sмith, C. M. Excitation by ethanol of rat muscle spindles. Journal of Pharmacology and Experimental Therapeutics, 1971, 179, 301-311.

Meyer-Lohman, J., Hagenah, R., Hellweg, L., \& Benecke, $R$. The action of ethyl alcohol on the activity of individual Renshaw cells. Nauyn-Schmiedeberg's Archives Pharmacology, 1972, 272, 131-142.

Moore, J. W., Ulbricht, W., \& Takata, M. Effect of ethanol on sodium and potassium conductances of the squid axon membrane. Journal of General Physiology, 1964, 48, 279-293.

OKADA, K. Effects of alcohols and acetone on the neuromuscular junction of the frog. Japanese Journal of Physiology, 1967, 17, 245-257.

Pearson, J. A., \& MacDonald, J. F. Habituation of the flexor reflex: Inhibitory build-up or synaptic depression? Brain Research, 1973, 53, 451-454.

Phillis, J. W., \& Jharmandas, K. The effects of chlorpromazine and ethanol on in vivo release of acetylcholine from the cerebral cortex. Comparative General Pharmacology, 1971, 2, 306-311.

Pinsker, H., Kupfermann, I., Castellucci, V., \& Kandel, E. R. Habituation and dishabituation of the gill-withdrawal reflex in Aplysia. Science, 1970, 167, 1740-1742.

Ritchie, J. M. The aliphatic alcohols. In L. Goodman \& A. Gilman (Eds.), The pharmacological basis of therapeutics. New York: Macmillan, 1975.

Spencer, W. A., Thompson, R. F., \& Neilson, D. R., JR. Decrement of ventral root electrotonus and intracellularly recorded PSPs produced by iterated cutaneous afferent volleys. Journal of Neurophysiology, 1966, 29, 253-274.

Stevens, R. J. Inhibition in the frog optic tectum (Doctoral dissertation, University of Illinois, 1969). Dissertation Abstracts 
International, 1970, 31, 540B. (University Microfilms No. 70-13, 504)

Thompson, R. F., \& Spencer, W. A. Habituation: A model phenomenon for the study of neuronal substrates of behavior. Psychological Review, 1966, 73, 16-43.

WALL, P. D. Habituation and post-tetanic potentiation in the spinal cord. In G. Horn \& R. A. Hinde (Eds.), Short term changes in neural activity and behavior. New York: Cambridge University Press, 1970.

Wass, J. A., \& Kaplan, H. M. Methoxyflurane anesthesia for Rana pipiens. Laboratory Animal Science, 1974, 24, 669-671.

WiCKelgren, B. G. Habituation of spinal motoneurons. Journal of Neurophysiology, 1967, 30, 1404-1423.

ZuCKe R, R. S. Crayfish escape behavior and central synapses. II. Physiological mechanisms underlying behavioral habituation. Journal of Neurophysiology, 1972, 35, 621-637.

\section{NOTES}

1. We are indebted to I. Gormezano, whose development of the restraining apparatus and initial research into the frog nictitating membrane preparation were supported by NSF Grant BNS 76-84561.

2. Rinaldi and Thompson (Note 2) have measured blood alcohol levels (BALs) in bullfrogs (Rana catesbeiana) that were maintained in either $.1 \%$ or $1.0 \%$ ethyl alcohol solutions for 2 weeks. Those housed in $.1 \%$ showed BALs of $21.34 \mathrm{mg} / 100 \mathrm{ml}$ (milligram percent), while those in $1.0 \%$ alcohol had BALs of 300.7 milligram percent. Twenty-four hours after removal of the animals from the alcohol solution and return to their normal housing conditions, the $.1 \%$ animals showed no trace of blood alcohol, whereas the $1.0 \%$ animals still maintained a BAL of 33 milligram percent. Although the conditions of their experiment were different from ours, these data may serve as a first approximation of the BALs in our animals following $2.5 \mathrm{~h}$ immersion in dilute alcohol solution.
(Received for publication April 22, 1980; revision accepted August 14, 1980.) 